\title{
EDUCAÇÃO AMBIENTAL CRÍTICA NA FORMAÇÃO DE PROFESSORES: UMA REVISÃO SISTEMÁTICA DE LITERATURA
}

\author{
CRITICAL ENVIRONMENTAL EDUCATION IN TEACHER EDUCATION: A \\ SYSTEMATIC REVIEW OF THE LITERATURE
}

\author{
Ynaiara Kristhine Stopa da $\mathrm{Cruz}^{1}$, Rodrigo de Souza Poletto ${ }^{2}$, Thaynara Aparecida Machado ${ }^{3}$,
} Dayanne da Silva Alves ${ }^{4}$

Recebido: novembro/2019 Aprovado: dezembro/2020

\begin{abstract}
Resumo: Este trabalho apresenta os resultados de uma revisão sistemática de literatura (RSL) que teve como objetivo observar e analisar de que forma a Educação Ambiental Crítica está sendo abordada na formação inicial e continuada de professores. A investigação foi realizada por meio de trabalhos publicados nos seguintes bancos de dados: Biblioteca Digital de Teses e Dissertações do Instituto Brasileiro de Informação e Ciências e Tecnologia, Banco de Teses e dissertações da Coordenação de Aperfeiçoamento de Pessoal de Nível Superior - CAPES e nas revistas qualificadas na área de Ensino em A1, A2 e B1 entre 2000 e 2018. Como resultados dos 7.460 trabalhos analisados, somente 16 abordavam a temática, de formação de professores, visando reconstruir conceitos, superar o reducionismo e refletir sobre os aspectos políticos, econômicos, sociais e ambientais acerca da temática, portanto os resultados evidenciam a carência nas publicações a respeito da Educação Ambiental Crítica na formação inicial e continuada de professores.
\end{abstract}

Palavras-chave: Educação Ambiental Crítica; formação de professores; ciências biológicas.

\begin{abstract}
This paper presents the results of a systematic literature review (RSL) that aimed to observe and analyze how Critical Environmental Education is being addressed in initial and continuing teacher education. The research was carried out through works published in the following databases: Digital Library of Theses and Dissertations of the Brazilian Institute of Information and Science and Technology, Bank of Theses and dissertations of the Coordination for the Improvement of Higher Education Personnel - CAPES and in the journals. in the area of Education in A1, A2 and B1 between 2000 and 2018. As a result of the 7,460 papers analyzed, only 16 addressed the theme of teacher education, aiming to reconstruct concepts, overcome reductionism and reflect on political, economic, social and environmental issues about the theme, therefore the results show the lack in the publications about Critical Environmental Education in the initial and continuous formation of teachers.
\end{abstract}

Keywords: Critical Environmental Education; teacher training; biological sciences.

\footnotetext{
1 (iD) https://orcid.org/0000-0003-3318-7046 - Mestre em Ensino pelo Programa de Pós-Graduação em Ensino, Universidade Estadual do Norte do Paraná (PPGEN-UENP), Cornélio Procópio, Paraná, Brasil. Endereço: Rua Antonio Cassiano, 232, Jd. Bela Vista, CEP: 86300-000, Cornélio Procópio, Paraná, Brasil.E-mail: ynaiara_stopa@hotmail.com.

2 (iD) https://orcid.org/0000-0002-7034-7865 - Doutor pelo Programa de Pós-Graduação em Ciências Biológicas (Botânica) Universidade Estadual Paulista Júlio de Mesquita Filho (UNESP), Professor do Programa de Pós-Graduação em Ensino (PPGEN) na Universidade Estadual do Norte do Paraná (UENP), Cornélio Procópio, Paraná, Brasil. Endereço: Rua José Luis Mendes, 148, Jardim São Silvestre, CEP: 86300-000, Cornélio Procópio, Paraná, Brasil. E-mail: rodrigopoletto@uenp.edu.br.

3 (iD https://orcid.org/0000-0003-3453-330X - Mestre em Ensino pelo Programa de Pós-Graduação em Ensino, Universidade Estadual do Norte do Paraná (PPGEN-UENP), Cornélio Procópio, Paraná, Brasil. Endereço: Rua Laurindo Guillen Hurtado, 260, Vale Verde, CEP: 86300-000, Cornélio Procópio, Paraná, Brasil. E-mail: thaynara.apmachado@gmail.com.

4 (iD https://orcid.org/0000-0003-3775-1919 - Doutoranda pelo Programa de Pós-graduação de Ensino de Ciências e Educação Matemática, Universidade Estadual de Londrina, Londrina, Paraná, Brasil. Endereço: Rua Antônio Pedoti, 106, Jd. Veneza, CEP: 86.300-000, Cornélio Procópio, Paraná, Brasil.E-mail: dayanne_silvaalves@hotmail.com.
} 


\section{Introdução}

Desde a Revolução Industrial, a relação do homem com a natureza vem se intensificando, resultando na grande degradação ambiental (MORALES, 2009). Nesse sentido a Educação Ambiental (EA) surgiu como mediadora à problemática socioambiental e na busca por uma relação equilibrada entre as concepções socioeconômicas com o meio ambiente, sendo um processo educativo de extrema importância para formação cidadã (GUIMARÃES, 2004; MORALES, 2009).

Dias (2010) conceitua a EA como um conjunto de conteúdos e práticas ambientais, orientadas para a resolução dos problemas concretos do ambiente, por meio do enfoque interdisciplinar e de uma participação ativa e responsável de cada indivíduo e da comunidade. Assim, não cabe mais uma visão reducionista do conceito de EA, na qual são privilegiadas apenas as questões relativas ao meio ambiente, restringindo as atividades relacionadas à EA ao ensino da ecologia.

Desse modo, a Educação Ambiental Crítica (EAC) busca romper as características conservadoras da sociedade, pois ao falarmos em EAC é afirmar a educação enquanto práxis social que favoreça a construção de uma nova sociedade, na qual a sustentabilidade da vida, a atuação política consciente e a construção de uma ética ecológica seja sua essência, que visa à autonomia e a liberdade dos agentes sociais por uma intervenção transformadora (LOUREIRO, 2012).

Visto que, a formação de educadores ambientais pode auxiliar na conscientização e compreensão das questões ambientais para além dos aspectos biológicos, físicos e químicos, as questões sócio-políticas, demandam uma formação de "consciência ambiental" e o exercício pleno da cidadania (PENTEADO, 2007).

De acordo com as Diretrizes Curriculares Nacionais da Educação Ambiental (BRASIL, 2012), a Educação Ambiental deve ser transdisciplinar, ou seja, deve perpassar todas as áreas do conhecimento. Nesse mesmo sentido a Política Nacional de Educação Ambiental número 9597/99, em seu artigo 20, afirma que "A educação ambiental é um componente essencial e permanente da educação nacional, devendo estar presente, de forma articulada, em todos os níveis e modalidades do processo educativo, em caráter formal e não-formal" (BRASIL, 1999).

No entando apesar das diretrizes e leis salientando a relavância da inserção da Educação Ambiental na formação de professores, muitos cursos de formação inicial e continuada não se adaptaram para tais necessidade ainda.

Diante do exposto, e pela pertinência da temática, sentiu-se a necessidade de realizar uma Revisão Sistemática de Literatura com o objetivo de evidenciar e analisar a produção científica nacional referente à Educação Ambiental Crítica na formação de professores. Para tal, foram pesquisados trabalhos publicados no Banco de teses e Dissertações da Coordenação de Aperfeiçoamento de Pessoal de Nível Superior (CAPES) e da Biblioteca Digital de Teses e Dissertações (BDTD) e nas revistas qualificadas na área de Ensino, com conceito Qualis A1, A2 e B1 (elencadas na Plataforma Sucupira - Qualis quadriênio 2013-2016), buscando quantificar e analisar os trabalhos que abordavam a temática Educação Ambiental Crítica e formação de 
professores, para assim promover um mapeamento da área, visando que essa pesquisa possa instigar e viabilizar trabalhos futuros.

\section{Materiais e Métodos}

O método utilizado nesta pesquisa baseou-se na Revisão Sistemática de Literatura (RSL) de Kitchenham (2007), que compreende que uma revisão visa identificar, avaliar e interpretar todas as pesquisas que sejam relevantes para uma questão específica, área temática ou fenômeno interessante. Desse modo, o protocolo utilizado nesta pesquisa foi adaptado de informações baseadas no trabalho de Kitchenham (2007).

1. Identificação e Planejamento da Pesquisa: nesta etapa foram definidas as questões de pesquisa, as fontes de busca e os critérios de inclusão e exclusão dos trabalhos, foram elaboradas a seguinte questão: QP1: A Educação Ambiental Crítica está presente na formação inicial e continuada de professores? QP2: De que forma a Educação Ambiental Crítica está sendo trabalhada na formação inicial e continuada de professores?

Para contemplar as perguntas norteadoras desta pesquisa, as informações foram coletadas das seguintes bases de dados: a primeira foi a Biblioteca Digital Brasileira de Teses e Dissertações do Instituto Brasileiro de Informação em Ciência e Tecnologia (BDTD), a segunda pesquisa foi no Banco de Teses e Dissertações da Coordenação de Aperfeiçoamento de Pessoal de Nível Superior (CAPES), a terceira foi em periódicos que estão no índice restrito da área de Ensino, com conceito Qualis A1, A2 e B1. Estes periódicos foram elencados por meio da Plataforma Sucupira, na classificação de periódicos Quadriênio 2013-2016, tendo como intervalo de tempo os anos de 2000 a 2018, podendo haver alterações, caso a pesquisa seja refeita após essa data.

A forma de busca foi manual, tendo como critério de inclusão a leitura dos títulos dos trabalhos que apresentavam as palavras "Educação Ambiental Crítica" e "formação de professores", para assim restringirmos as pesquisas que dispunham o uso desse tema no contexto do ensino. Foram analisadas somente revistas de língua portuguesa, as quais foram selecionadas conforme a concentração voltada ao Ensino de Ciências.

2. Seleção de estudos primários: nesta etapa foi realizada a seleção dos trabalhos que apresentavam no título as palavras-chave "Educação Ambiental Crítica", "formação de professores", "formação inicial" e "formação continuada". Concluída essa etapa, realizou-se a leitura dos resumos, como critério de exclusão, descartaram-se os artigos que não tratavam da temática.

3. Estudo da avaliação de qualidade e 4. Extração e monitorização de dados: nestas etapas foram realizadas as leituras e averiguações dos trabalhos selecionados nos estudos primários para garantir a pertinência dos mesmos com a temática pesquisada.

5. Síntese de dados: seleção final dos trabalhos pertinentes. Os dados extraídos estão evidenciados na seção a seguir. 


\section{Resultados e Discussões}

Ao realizar a primeira pesquisa na Biblioteca Digital Brasileira de Teses e Dissertações (BDTD) com a palavra-chave "Educação Ambiental Crítica", foram encontrados 157 trabalhos, dentre os quais se realizou as exclusões primeiramente pela análise de seus títulos, posteriormente a leitura de seus respectivos resumos para a exclusão daqueles que também não tratavam de Educação Ambiental Crítica na formação de professores. Desta forma, restaram 4 trabalhos que estão expostos na Tabela 1.

Tabela 1: Teses e Dissertações da BDTD

\begin{tabular}{|c|c|c|c|c|}
\hline № & $\begin{array}{c}\text { Título do Trabalho de } \\
\text { pesquisa }\end{array}$ & Autor/Ano & $\begin{array}{c}\text { Programa de } \\
\text { Pesquisa }\end{array}$ & Tipicidade \\
\hline 1 & $\begin{array}{l}\text { Educação ambiental crítica } \\
\text { e formação de professores: } \\
\text { construção coletiva de uma } \\
\text { proposta na escola pública }\end{array}$ & $\begin{array}{l}\text { Jorge Sobral da Silva } \\
\text { Maia (2011) }\end{array}$ & $\begin{array}{l}\text { Programa de Pós- } \\
\text { Graduação em } \\
\text { Educação para a } \\
\text { Ciência- UNESP }\end{array}$ & Tese \\
\hline 2 & $\begin{array}{c}\text { A educação ambiental } \\
\text { crítica e sua construção na } \\
\text { escola pública: } \\
\text { compreendendo } \\
\text { contradições pelos } \\
\text { caminhos da formação de } \\
\text { professores }\end{array}$ & $\begin{array}{l}\text { Daniele Cristina de } \\
\text { Souza (2014) }\end{array}$ & $\begin{array}{l}\text { Programa de Pós- } \\
\text { Graduação em } \\
\text { Educação para a } \\
\text { Ciência- UNESP }\end{array}$ & Tese \\
\hline 3 & $\begin{array}{l}\text { A formação continuada de } \\
\text { professores em serviço em } \\
\text { educação ambiental por } \\
\text { meio da pesquisa-ação } \\
\text { participante }\end{array}$ & $\begin{array}{l}\text { Leticia Zuleica de Lima } \\
\text { Scherk (2014) }\end{array}$ & $\begin{array}{l}\text { Programa de pós- } \\
\text { graduação em } \\
\text { ensino, história e } \\
\text { filosofia das ciências } \\
\text { e da matemática- } \\
\text { UFABC }\end{array}$ & Dissertação \\
\hline 4 & $\begin{array}{c}\text { Ações de formação } \\
\text { continuada, baseadas na } \\
\text { pedagogia dialógica, para a } \\
\text { inserção da Educação } \\
\text { Ambiental crítica em } \\
\text { escolas públicas. }\end{array}$ & $\begin{array}{c}\text { Talita Mazzini Lopes } \\
\text { (2018) }\end{array}$ & $\begin{array}{l}\text { Programa de Pós- } \\
\text { Graduação em } \\
\text { Educação Escolar- } \\
\text { UNESP/Araraquara }\end{array}$ & Tese \\
\hline
\end{tabular}

Fonte: Os autores (2019)

Maia (2011) em sua tese seguindo a metodologia de pesquisa-ação elaborou um projeto de educação ambiental na perspectiva sócio-crítica, com intuito de auxiliar na formação de um grupo de professores pesquisadores do ensino fundamental de uma escola estadual para um processo de reflexão-ação-reflexão sobre suas práticas. Foram elaborados dois projetos de pesquisa pelos professores, que também promovia a participação da comunidade escolar, as ações expandiram para a comunidade no entorno possibilitando o enfrentamento das questões socioambientais característico da educação ambiental fundamentada em princípios críticos. Concluiu-se assim que a pesquisa-ação permitiu construir, com os professores, estratégias para o enfrentarem situações relacionadas à sua prática social e pedagógica evidenciado que a escola e o trabalho educativo são os elementos ideias para criar um campo teórico necessário para a construção da educação ambiental crítica na formação de educadores ambientais.

Souza (2014) elucida as práticas fragilizadas, desconectadas da Educação Ambiental nas escolas públicas sustentadas em uma perspectiva de educação conservacionista e pragmática. Desta maneira o autor dividiu sua pesquisa em duas fases a primeira foi um curso de formação 
em parceria com a Secretaria de Educação do Estado de São Paulo, visando à problematização do currículo oficial e da Educação Ambiental Crítica na escola. Na segunda fase da pesquisa foi realizado uma intervenção em uma escola pública, com os alunos por meio de observação participante, do diário de campo, registros escritos dos alunos, fotos, vídeos e uma entrevista semiestruturada e o conhecimento foi focado na realidade escolar e suas relações social a partir da abordagem do tema Violência Escolar: um tema para a formação em Educação Ambiental Crítica, juntamente com a professora.

Scherk (2014) por meio de uma pesquisa-ação-participativa em uma escola municipal de São Paulo foi realizado uma formação continuada e a constituição de um grupo de estudo em Educação Ambiental realizada em Jornada Especial Integral de Formação, com os professores. Os resultados mostraram avanços relacionados à constituição de um espaço de diálogo que se fez no horário de formação coletiva, no reconhecimento de novas práticas e também quanto ao contexto no qual a escola está inserida, levando à discussão de problemas ambientais locais. No entanto foi verificado que ainda faltam elementos de apropriação de uma perspectiva crítica da educação ambiental pelo coletivo, devendo assim dar continuidade ao curso, pois foi verificado pela pesquisadora um processo lento de apropriação da educação ambiental em uma perspectiva crítica pelos professores.

Lopes (2018) em sua pesquisa teve como objetivo desenvolver, aplicar e avaliar as contribuições de uma proposta de formação continuada de professores, baseada na pedagogia dialógica freireana, para as práticas de EA desenvolvidas em escolas públicas por meio da pesquisa-participante. De acordo com os sujeitos da pesquisa apesar das dificuldades para inserção da EA no ambiente escolar por meio da metodologia do tema gerador, essa metodologia proporciona a participação e o engajamento dos educandos nas atividades propostas. A partir disso concluiu-se que a pedagogia dialógica e a metodologia do Tema gerador, utilizadas como proposta de formação contribui para a inserção de práticas de EA críticas nas escolas.

Para a segunda pesquisa, no portal de periódicos da CAPES, foi utilizada a palavra-chave "Educação Ambiental Crítica". Dessa busca retornou um total de 388 trabalhos que continham a palavra-chave no título, dentro os quais se realizaram as exclusões primeiramente pela análise do título, posteriormente a leitura de seus resumos para exclusão daqueles que também não tratavam de Educação Ambiental Crítica, na formação inicial ou continuada de professores. Assim restaram 7 trabalhos que estão expostos na Tabela 2.

Tabela 2 - Teses e dissertações da CAPES

\begin{tabular}{|c|c|c|c|c|}
\hline No & $\begin{array}{c}\text { Título do Trabalho de } \\
\text { pesquisa }\end{array}$ & Autor/Ano & $\begin{array}{c}\text { Programa de } \\
\text { Pesquisa }\end{array}$ & Tipicidade \\
\hline 1 & $\begin{array}{c}\text { Formação continuada para } \\
\text { uma educação ambiental } \\
\text { crítica: concepções de } \\
\text { professores do ensino } \\
\text { fundamental do município } \\
\text { do Rio de Janeiro }\end{array}$ & $\begin{array}{c}\text { Andressa Goncalves } \\
\text { Rocha (2016) }\end{array}$ & $\begin{array}{c}\text { Programa de Pós- } \\
\text { Graduação em } \\
\text { Ensino em } \\
\text { Biociências E Saúde } \\
\text { - FIOCRUZ }\end{array}$ & Dissertação \\
\hline 2 & $\begin{array}{l}\text { A formação de educadores } \\
\text { ambientais críticos em um }\end{array}$ & $\begin{array}{c}\text { Eliane Aparecida Toledo } \\
\text { Pinto (2016) }\end{array}$ & $\begin{array}{c}\text { Programa de Pós- } \\
\text { Graduação em }\end{array}$ & Tese \\
\hline
\end{tabular}




\begin{tabular}{|c|c|c|c|c|}
\hline & $\begin{array}{c}\text { curso de Pedagogia: limites } \\
\text { e possibilidades }\end{array}$ & & $\begin{array}{l}\text { Educação para a } \\
\text { Ciência- UNESP }\end{array}$ & \\
\hline 3 & $\begin{array}{l}\text { Educação ambiental crítica } \\
\text { e formação de professores } \\
\text { fundada na investigação- } \\
\text { ação e na parceria } \\
\text { colaborativa }\end{array}$ & $\begin{array}{l}\text { José Pedro de Azevedo } \\
\text { Martins } \\
(2016)\end{array}$ & $\begin{array}{l}\text { Programa de Pós- } \\
\text { Graduação em } \\
\text { Educação-UNIMEP }\end{array}$ & Tese \\
\hline 4 & $\begin{array}{l}\text { Formação de professores } \\
\text { em contexto para o } \\
\text { desenvolvimento de } \\
\text { práticas de educação } \\
\text { ambiental crítica na escola }\end{array}$ & $\begin{array}{l}\text { Tatiane Guimarães de } \\
\text { Oliveira Ribeiro } \\
\text { (2016) }\end{array}$ & $\begin{array}{c}\text { Programa de } \\
\text { Mestrado } \\
\text { Profissional em } \\
\text { Ensino de Ciências e } \\
\text { Matemática - IFSP }\end{array}$ & Dissertação \\
\hline 5 & $\begin{array}{c}\text { Educação ambiental e } \\
\text { formação de professores } \\
\text { para a conservação da } \\
\text { fauna do Parque Estadual } \\
\text { das Fontes do Ipiranga (PEFI } \\
\text { - SP). }\end{array}$ & $\begin{array}{c}\text { Nathalia Formenton da } \\
\text { Silva (2018) }\end{array}$ & $\begin{array}{l}\text { Programa de Pós- } \\
\text { graduação em } \\
\text { Conservação da } \\
\text { Fauna -UFSCar }\end{array}$ & Dissertação \\
\hline 6 & $\begin{array}{l}\text { Educação Ambiental Crítica: } \\
\text { círculos de cultura na } \\
\text { formação continuada } \\
\text { docente }\end{array}$ & $\begin{array}{l}\text { Laryssa Abilio Oliveira } \\
\text { (2018) }\end{array}$ & $\begin{array}{l}\text { Programa de Pós- } \\
\text { Graduação em } \\
\text { Educação - UFPB }\end{array}$ & Tese \\
\hline 7 & $\begin{array}{l}\text { Os processos críticos } \\
\text { colaborativos em educação } \\
\text { ambiental na formação } \\
\text { continuada de professores } \\
\text { contextualizada para o } \\
\text { seminário paraibano. }\end{array}$ & $\begin{array}{l}\text { Hugo da Silva Florentino } \\
\qquad(2018)\end{array}$ & $\begin{array}{l}\text { Programa de Pós- } \\
\text { Graduação em } \\
\text { Educação-FPB }\end{array}$ & Tese \\
\hline
\end{tabular}

Fonte: Os autores (2019)

Rocha (2016) em sua pesquisa teve como objetivo principal promover um curso de formação continuada para professores do ensino fundamental, fornecendo subsídios teóricos e metodológicos para a prática docente que remetesse a um sentido mais crítico da Educação Ambiental. Os resultados apontaram pequenos avanços nos conceitos de meio ambiente, anulando a visão naturalista e ampliando o conceito globalizante, apesar da predominância do olhar antropocêntrico, e quanto à educação ambiental, houve um aumento da tendência alternativa e uma redução da concepção tradicional. $O$ autor acredita que o curso contribui para motivar os professores a novas formações na área de educação ambiental.

Pinto (2016) em sua tese teve como objetivo identificar e analisar em que medida o processo de formação de futuros professores de um curso de Pedagogia pode contribuir para que possam atuar, futuramente, como educadores ambientais críticos. A pesquisa foi desenvolvida com estudantes de pedagogia, e teve 4 etapas: 1 ) análise do projeto político pedagógico (PPP) do curso de Pedagogia e dos planos de ensino das disciplinas cujos conteúdos contemplavam as questões socioambientais, utilizando a análise de conteúdo (temática); 2) investigação da trajetória formativa em Educação Ambiental (EA) dos alunos participantes; 3 ) formação e aporte teórico/prático nas disciplinas oferecidas no curso de Pedagogia que trabalham a EA; 4) desenvolvimento de uma pesquisa participativa com os alunos no município de Ibitinga, como pesquisadores-colaboradores, articulando os conteúdos teóricos à prática, visando a que pudessem se tornar futuros agentes transformadores da realidade. A pesquisa permitiu aos estudantes vivenciarem na prática um problema ambiental do município e os seus 
condicionantes, e contribuiu para a formação enquanto futuros educadores ambientais. De acordo com o autor trabalhar a questão ambiental no processo formativo de professores do curso de Pedagogia permitiu criar novas possibilidades de reflexão, partilhas, constatações, descobertas e (re) leituras da EA, além de apontar também algumas dificuldades e limitações, tais como: estrutura do curso de Pedagogia, o contexto acadêmico, a falta de articulação entre o poder público e a faculdade e a formação do aluno. Dessa forma o autor concluiu que a formação crítica exige que o processo seja permanente, para preparar os futuros educadores para a superação da "armadilha paradigmática" à qual ainda se encontram aprisionados, relacionada à formação que receberam ao longo de suas vidas escolares e à qual estão implementadas e refletem nas práticas educativas ambientais.

Martins (2016) desenvolveu um programa de formação continuada por meio da investigação-ação e da parceria Colaborativa e formou um grupo composto por professoras escolares, professoras universitárias e estudantes de graduação, que foi denominado de Grupo de Pesquisa Universidade-Escola para trabalhar temas ambientais e investigar as dificuldades e estratégias de ensino, visando inserir a educação ambiental crítica no ensino fundamental. 0 grupo se reuniu durante um ano, realizando três tipos de atividades: Oficinas de Formação e Diagnósticos (OFD), Ação Escolar de Ensino e Pesquisa (AEP) e Oficinas de Socialização das Experiências (OSE). No final o autor conclui que os professores foram modificando suas práticas ao longo da formação, que inicialmente eram pontuais e compartimentalizadas, para práticas das quais a temáticas socioambientais passaram a serem abordadas levando em consideração os aspectos econômicos, sociais, políticos e culturais potencializando um processo de melhoria do ensino escolar.

Ribeiro (2016) utilizou a pesquisa-ação como estratégia para formação de professores de uma escola de educação infantil, devido à urgência em se formar cidadãos emancipados, críticos e transformadores da realidade socioambiental, a educação escolar apresenta-se como uma possibilidade de apropriação de conhecimentos e valores que possam contribuir para o desenvolvimento e melhoria do modo de viver. Assim é necessário que os professores tenham claros os conceitos e fundamentos de educação ambiental para que suas práticas não sejam esvaziadas de conhecimentos e objetivos bem definidos. $O$ autor apontou que a formação possui o desafio de romper com as concepções tradicionais, tornando a mudança de prática e sua organização com base na concepção crítica um processo mais complexo, no entanto foi verificado que a formação realizada no contexto escolar sensibilizou professores que não trabalhavam com Educação Ambiental a se envolver, articular o coletivo e mobilizar ações de EA na escola. E que após a intervenção as ações e as práticas de EA na escola tornaram-se mais intencionais e havendo a promoção de momentos de reflexão coletiva e troca de experiências entre os docentes em busca de um objetivo comum, com vistas ao desenvolvimento de práticas de educação ambiental na escola que envolvesse a todos.

Silva (2018) propôs em seu trabalho elaborar e aplicar um curso de formação de professores, com base nos pressupostos da pesquisa-ação, em uma perspectiva de educação ambiental (EA) crítica, emancipatória e transformadora, para duas escolas localizadas no entorno do Parque Estadual das Fontes Ipiranga (PEFI), que apresenta mais de 210 espécies de vertebrados, no entanto, grande parte desta fauna está ameaçada por ações antrópicas em 
virtude de este estar inserido em uma área urbana. Alguns problemas são: risco de atropelamento, eletrocussão, caça e captura ilegal, transmissão de doenças e predação por animais domésticos invasores. $O$ intuito do curso era contribuir para a sensibilização e conscientização dos envolvidos, de modo que se interessem pelas questões ambientais do PEFI e se envolvam na luta pela conservação desta unidade de conservação. Assim, curso atendeu às principais características de cursos de formação continuada eficazes, contemplando, ainda que parcialmente, o conhecimento pedagógico do conteúdo, os métodos ativos de aprendizagem, a participação coletiva, a duração e a coerência.

Oliveira (2018) em sua tese desenvolveu uma proposta de educação ambiental crítica, a partir da metodologia dos círculos de cultura de Freire, constituindo espaços de formação continuada docente que possibilitem engajamento e integração em toda comunidade escolar. O estudo foi desenvolvido em uma escola pública com professores da escola e representantes da escola e da comunidade, foi desenvolvido em três turnos (manhã, tarde e noite), teve início em fevereiro de 2015 e foi até julho de 2018. Diante dos resultados obtidos pelo projeto, no decorrer dos anos, foi possível verificar melhorias contínua da qualidade de ensino da escola alvo da pesquisa, contribuindo para a implantação de uma modalidade de aprendizagem crítica e transformadora, alguns docentes já buscavam trabalhar a EA na escola, mas a faziam de forma isolada, disciplinar, entretanto, com a vivência das formações baseadas nos círculos de cultura e com a proposta das escolas sustentáveis, foi possível uma construção e vivência de projetos interdisciplinares, proporcionando uma experiência nova, pautada no que recomenda o tema.

Florentino (2018) em sua tese utilizou a metodologia de "pesquisa-ação crítico colaborativa" associada com os pressupostos epistemológicos da teoria freireana e moriniana articulada e complementada pela educação transdisciplinar e contextualizada para o Semiárido, como forma de despertar o pensar articulado pela transcendência no agir. A pesquisa foi realizada com professores que lecionam do 4ํa ao 9 do Ensino Fundamental de escolas públicas de Santa Helena, Semiárido paraibano. O autor observou em seus resultados um saber (percepção) docente centrado na epistemologia conservacionista e/ou pragmática, marcada por limites de natureza teórica, prática e relacional, provavelmente influenciado pelo paradigma tradicional moderno vivenciado nos processos formativos (inicial e continuado) que fragmenta as dimensões do sujeito e da realidade. E com a realização da pesquisa-formação, observou a composição de um cenário de práxis crítica e relacional entre os professores na compreensão (reflexão) e na intervenção (ação) nas escolas onde ensinam e, assim, sugerindo que processos formativos críticos-colaborativos podem estimular um redimensionamento do ser na sua relação conhecer a realidade multidimensional (social, cultural, políticas, histórica, ética e ambiental) vivenciada.

Na terceira pesquisa, com objetivo de ampliar ainda mais à busca de trabalhos, realizouse um mapeamento das produções científicas publicadas em algumas das principais revistas/periódicos qualificados como A1, A2 e B1 na plataforma Plataforma Sucupira - Qualis periódicos quadriênio 2013-2016, na área de Ensino, com intervalo de tempo os anos de 2000 a 2018, ou seja, nos últimos dezoito anos. Foram analisadas apenas revistas de língua portuguesa, selecionando os artigos relacionados ao ensino que continham as palavras chaves "Educação Ambiental Crítica" e "formação de professores" no título. 
Após a seleção dos periódicos, empreendeu-se leitura e análise detalhada dos títulos dos artigos (um a um) elencados no sumário das publicações dos periódicos, descartando os artigos que não tratavam de Educação Ambiental Crítica na formação de professores. Os artigos selecionados foram lidos e analisados. Ao se perceber que alguns títulos não estavam bem claros a abordagem de Educação Ambiental na formação de professores, foi dada uma atenção especial aos resumos dos artigos. A Tabela 3 apresenta uma síntese dos resultados dessa última etapa de tomada de dados.

Tabela 3: Mapeamento dos Artigos nos Periódicos.

\begin{tabular}{|c|c|c|c|c|c|c|}
\hline Periódicos & Qualis & ISSN & $\begin{array}{c}\text { Período de } \\
\text { levantamento }\end{array}$ & $\begin{array}{c}\text { Quantidade } \\
\text { de } \\
\text { exemplares }\end{array}$ & $\begin{array}{c}\text { Quantidad } \\
\text { e de } \\
\text { artigos }\end{array}$ & $\begin{array}{c}\text { Total de } \\
\text { artigos que } \\
\text { abordam o } \\
\text { tema }\end{array}$ \\
\hline $\begin{array}{c}\text { Ciência \& } \\
\text { Educação } \\
\text { (Bauru) }\end{array}$ & A1 & $\begin{array}{l}1980- \\
850 X\end{array}$ & $\begin{array}{l}2000 \text { a } 2018 \\
\text { V. } 6 \text { ao V. } 24\end{array}$ & 61 & 802 & 2 \\
\hline $\begin{array}{c}\text { Ensaio: } \\
\text { Pesquisa em } \\
\text { Educação em } \\
\text { Ciências } \\
\end{array}$ & A1 & $\begin{array}{l}1983- \\
2117\end{array}$ & $\begin{array}{l}2000 \text { a } 2018 \\
\text { V. } 2 \text { ao V. } 20\end{array}$ & 45 & 385 & 0 \\
\hline $\begin{array}{c}\text { Investigações } \\
\text { em Ensino de } \\
\text { Ciências }\end{array}$ & $A 2$ & $\begin{array}{l}1518- \\
8795\end{array}$ & $\begin{array}{l}2000 \text { a } 2018 \\
\text { V. } 5 \text { ao V. } 23\end{array}$ & 57 & 454 & 0 \\
\hline $\begin{array}{c}\text { Acta Scientiae: } \\
\text { Revista de } \\
\text { Ensino de } \\
\text { Ciências e } \\
\text { Matemática }\end{array}$ & $\mathrm{A} 2$ & $\begin{array}{l}2178- \\
7727\end{array}$ & $\begin{array}{l}2000 \text { a } 2018 \\
\text { V. } 2 \text { ao V. } 20\end{array}$ & 51 & 494 & 0 \\
\hline $\begin{array}{c}\text { Alexandria: } \\
\text { Revista de } \\
\text { Educação em } \\
\text { Ciência e } \\
\text { Tecnologia }\end{array}$ & $\mathrm{A} 2$ & $\begin{array}{l}1982- \\
5153\end{array}$ & $\begin{array}{l}2000 \text { a } 2018 \\
\text { V. } 1 \text { ao V. } 11\end{array}$ & 29 & 296 & 0 \\
\hline $\begin{array}{c}\text { Revista } \\
\text { Brasileira de } \\
\text { Pesquisa em } \\
\text { Educação em } \\
\text { Ciências } \\
\end{array}$ & $\mathrm{A} 2$ & $\begin{array}{l}1806- \\
5104\end{array}$ & $\begin{array}{l}2000 \text { a } 2018 \\
\text { V.1 ao V.18 }\end{array}$ & 54 & 481 & 1 \\
\hline $\begin{array}{l}\text { Amazônia - } \\
\text { Revista de } \\
\text { Educação em } \\
\text { Ciências e } \\
\text { Matemáticas }\end{array}$ & $\mathrm{A} 2$ & $\begin{array}{l}2317- \\
5125\end{array}$ & $\begin{array}{l}2000 \text { a } 2018 \\
\text { V. } 1 \text { ao V. } 14\end{array}$ & 24 & 221 & 0 \\
\hline $\begin{array}{c}\text { Areté - } \\
\text { Revista } \\
\text { Amazônica de } \\
\text { Ensino de } \\
\text { Ciências }\end{array}$ & $\mathrm{A} 2$ & $\begin{array}{l}1984- \\
7505\end{array}$ & $\begin{array}{l}2000 \text { a } 2018 \\
\text { V. } 1 \text { ao V. } 11\end{array}$ & 24 & 372 & 0 \\
\hline $\begin{array}{l}\text { Rencima - } \\
\text { Revista de } \\
\text { Ensino de } \\
\text { Ciências e } \\
\text { Matemática }\end{array}$ & $A 2$ & $\begin{array}{l}2179- \\
426 X\end{array}$ & $\begin{array}{c}2000 \text { a } 2018 \\
\text { V.1 ao V. } 9\end{array}$ & 30 & 341 & 0 \\
\hline
\end{tabular}


DOI: http://dx.doi.org/10.31512/encitec.v11i1.381

\begin{tabular}{|c|c|c|c|c|c|c|}
\hline $\begin{array}{c}\text { Revista } \\
\text { Brasileira de } \\
\text { Ensino de } \\
\text { Ciência e } \\
\text { Tecnologia }\end{array}$ & $\mathrm{A} 2$ & $\begin{array}{l}1982- \\
873 X\end{array}$ & $\begin{array}{l}2000 \text { a } 2018 \\
\text { V. } 1 \text { ao V.11 }\end{array}$ & 34 & 399 & 0 \\
\hline $\begin{array}{c}\text { Ensino de } \\
\text { Ciências e } \\
\text { Tecnologia em } \\
\text { Revista }\end{array}$ & B1 & $\begin{array}{l}2237- \\
4450\end{array}$ & $\begin{array}{c}2000 \text { a } 2018 \\
\text { V. } 1 \text { ao V.8 }\end{array}$ & 17 & 106 & 0 \\
\hline $\begin{array}{c}\text { Ciência em } \\
\text { Tela } \\
\end{array}$ & B1 & $\begin{array}{l}1984- \\
154 X\end{array}$ & $\begin{array}{l}2008 \text { a } 2018 \\
\text { V. } 1 \text { ao V.11 }\end{array}$ & 21 & 142 & 0 \\
\hline $\begin{array}{c}\text { Ciência \& } \\
\text { Ensino }\end{array}$ & B1 & $\begin{array}{c}1980- \\
8631\end{array}$ & $\begin{array}{l}2000 \text { a } 2018 \\
\text { V. } 8 \text { ao V. } 12\end{array}$ & 13 & 73 & 0 \\
\hline $\begin{array}{c}\text { Revista } \\
\text { Ciências \& } \\
\text { Ideias }\end{array}$ & B1 & $\begin{array}{l}2176- \\
1477\end{array}$ & $\begin{array}{c}2000 \text { a } 2018 \\
\text { V.1 a V.9 }\end{array}$ & 19 & 128 & 0 \\
\hline $\begin{array}{c}\text { Experiências } \\
\text { em Ensino de } \\
\text { Ciências }\end{array}$ & B1 & $\begin{array}{l}1982- \\
2413\end{array}$ & $\begin{array}{l}2000 \text { a } 2018 \\
\text { V.1 ao V.13 }\end{array}$ & 46 & 531 & 0 \\
\hline $\begin{array}{l}\text { TEAR - Revista } \\
\text { de Educação, } \\
\text { Ciência e } \\
\text { Tecnologia }\end{array}$ & B1 & $\begin{array}{l}2238- \\
8079\end{array}$ & $\begin{array}{l}2000 \text { a } 2018 \\
\text { V.1 ao V.13 }\end{array}$ & 14 & 205 & 0 \\
\hline $\begin{array}{c}\text { Pesquisa em } \\
\text { Educação } \\
\text { Ambiental }\end{array}$ & B1 & $\begin{array}{l}2177- \\
5807\end{array}$ & $\begin{array}{c}2006 \text { a } 2018 \\
\text { V. } 1 \text { aо } 13\end{array}$ & 23 & 239 & 1 \\
\hline $\begin{array}{l}\text { Ambiente \& } \\
\text { Educação: } \\
\text { Revista de } \\
\text { Educação } \\
\text { Ambiental }\end{array}$ & B1 & $\begin{array}{l}2238- \\
5533\end{array}$ & $\begin{array}{c}2000 \text { a } 2018 \\
\text { V. } 5 \text { aо } 23\end{array}$ & 27 & 350 & 1 \\
\hline \multirow[t]{2}{*}{$\begin{array}{c}\text { Revista } \\
\text { Eletrônica do } \\
\text { Mestrado em } \\
\text { Educação } \\
\text { Ambiental } \\
\text { (REMEA) }\end{array}$} & B1 & $\begin{array}{l}1517- \\
1256\end{array}$ & $\begin{array}{l}2000 \text { a } 2018 \\
\text { V. } 13 \text { ao } 35\end{array}$ & 46 & 896 & 0 \\
\hline & & & Totais & 635 & 6.915 & 05 \\
\hline
\end{tabular}

Fonte: Os autores (2019)

Conforme demostrado na Tabela 3, da pesquisa realizada em 16 periódicos na área de Ensino entre os anos de 2000 a 2018, classificados na Plataforma Sucupira como A1, A2 e B1 no Qualis 2013, dos 6.915 artigos encontrados, somente 05 artigos (Tabela3) estão relacionadas com Educação Ambiental Crítica na formação de professores, revelando um baixo número de publicações com essa temática. A respeito dos artigos encontrados segue uma breve análise:

Quadro 1 - Artigos da revista Ciência \& Educação, qualificada como A1 em ensino.

\begin{tabular}{|c|c|c|c|}
\hline Título & Autor(es) & Vol./Num./Ano & Periódico \\
\hline $\begin{array}{c}\text { A percepção do professor de } \\
\text { biologia e sua }\end{array}$ & $\begin{array}{c}\text { Guimarães, Simone S. } \\
\text { formação: educação ambiental } \\
\text { em questão }\end{array}$ & $18 / 03 / 2012$ & Ciência \\
M.; Inforsato, Edson C. & & Educação \\
\hline $\begin{array}{c}\text { Formação de professores em } \\
\begin{array}{c}\text { Educação Ambiental Crítica } \\
\text { centrada em pesquisa-ação e } \\
\text { parceria colaborativa }\end{array}\end{array}$ & Martins, José Pedro de & $24 / 03 / 2018$ & Ciência \\
& & & \& \\
\hline
\end{tabular}


Fonte: Os autores (2019)

No artigo de Guimarães e Inforsato (2012) “A percepção do professor de biologia e sua formação: educação ambiental em questão" identifica as percepções dos professores de Biologia e dos licenciandos concluintes de um curso de Ciências Biológicas, em relação à presença da Educação Ambiental em sua formação inicial. Os resultados indicaram que os professores de Biologia ainda necessitam de uma formação mais crítica em relação à educação ambiental, e que essa formação necessita estar mais presentes nas universidades e nas licenciaturas em Ciências Biológicas para assim formar profissionais que possam atuar efetivamente na formação cidadã para uma sociedade mais sustentável.

O artigo "Formação de professores em Educação Ambiental Crítica centrada em pesquisaação e parceria colaborativa" de Martins e Schnetzler (2018) analisou um programa de formação continuada em educação ambiental crítica direcionado na investigação-ação em parceria colaborativa. $O$ grupo era de professores da escola básica, sendo três professores universitários e quatro licenciandos, a formação teve duração de um ano com encontros quinzenais, na qual foram desenvolvidas três atividades: Oficinas de Formação e Diagnósticos, Ação Escolar de Ensino e Pesquisa e Oficinas de Socialização de Experiências. Foi possível observar que os professores foram aos poucos modificando suas práticas docentes, que inicialmente eram pontuais e compartimentalizadas e no decorrer da formação, tais práticas foram alteradas com a inclusão de temáticas socioambientais abordadas de forma crítica, contextualizada, permanente, contínua e participativa.

Quadro 2 - Artigo da Revista Brasileira de Pesquisa em Educação em Ciências, qualificada como A2 em ensino.

\begin{tabular}{|c|c|c|c|}
\hline Título & Autor(es) & Vol./Num./Ano & Periódico \\
\hline O processo de tomada de & Costa, Lorenna S. O.; & $17 / 03 / 2017$ & Revista \\
consciência e a formação de & Echeverría, Agustina R.; & & Brasileira De \\
conceitos da educação & Ribeiro, Francis L. & & Pesquisa Em \\
ambiental na formação inicial & & & Educação em \\
de professores de & & & \\
ciênciâncias
\end{tabular}

Fonte: Os autores (2019)

No artigo "O Processo de Tomada de Consciência e a Formação de Conceitos da Educação Ambiental na Formação Inicial de Professores de Ciências/Química" os autores por meio de uma pesquisa participante formaram um grupo de discussão ao longo de um semestre com licenciandos em química. $\mathrm{O}$ objetivo desse grupo era o de analisar, a partir dos pressupostos da teoria histórico-cultura, o processo de tomada de consciência e a formação de conceitos da educação ambiental na formação inicial desses professores. Ao final desse trabalho, foi possível observar como a formação conceitual é um processo, os grupos de discussões com momentos para estudos e debates podem contribuir no estabelecimento de novas relações conceituais por meio de acepções e ressignificações, desnaturalizando as relações socioambientais e contribuindo para o processo de reflexão e apropriação dos conceitos científicos.

Quadro 3-Artigos da revista Pesquisa em Educação Ambiental, qualificada como B1 em ensino.

\begin{tabular}{|c|c|c|c|}
\hline Título & Autor(es) & Vol./Num./Ano & Periódico \\
\hline $\begin{array}{c}\text { A formação de educadoras/es } \\
\text { ambientais a partir do Pibid: }\end{array}$ & $\begin{array}{c}\text { Tibúrcio, Gabriela S.; } \\
\text { Logarezzi, Amadeu J. M. }\end{array}$ & $12 / 02 / 2017$ & $\begin{array}{c}\text { Pesquisa } \\
\text { em }\end{array}$ \\
\hline
\end{tabular}


reflexões sobre limites e

possibilidades
Educação

Ambiental

Fonte: Os autores (2019)

O artigo de Tibúrcio e Logarezzi (2018) intitulado “A formação de educadoras/es ambientais a partir do Pibid: reflexões sobre limites e possibilidades" foi realizado grupos de discussões comunicativos com estudantes do curso de Ciências Biológicas e com uma professora de Ciências e Biologia da rede pública de ensino, sendo desenvolvida a partir das orientações da metodologia comunicativo-crítica. Com objetivo de colaborar com a produção de conhecimento sobre formação docente em educação ambiental em uma perspectiva crítica, a partir das experiências de um grupo do Pibid da Unesp de Rio Claro. Os resultados mostraram possibilidades viáveis de práticas de educação ambiental em uma perspectiva crítica, no contexto escolar, a partir do Pibid e, com isso, consideramos de grande importância programas de formação docente que ofereçam aos licenciandos um contato mais estreito com a escola, a partir de um trabalho coletivo e interdisciplinar.

Quadro 4 - Artigos da revista Ambiente \& Educação, qualificada como B1 em ensino.

\begin{tabular}{|c|c|c|c|}
\hline Título & Autor(es) & Vol./Num./Ano & Periódico \\
\hline As perspectivas de ambiente e & Rosa, Marcelo D.; & $22 / 02 / 2017$ & Ambiente \\
de Educação Ambiental nos & Nogueira, Marilac L. S.; & & \& \\
projetos de professores da & Souza, Jéssica P. T.; & & Educação: \\
Educação Básica em um curso & Rocha, Pedro N.; Rink, & & Revista de \\
de formação continuada. & Juliana; Viveiro, & & Educação \\
& Alessandra A. & & Ambiental \\
\hline
\end{tabular}

Fonte: Os autores (2019)

No artigo "As perspectivas de ambiente e de Educação Ambiental nos projetos de professores da Educação Básica em um curso de formação continuada", foi abordado à questão das concepções de ambiente e de Educação Ambiental Crítica em propostas produzidas por professores em exercício na Educação Infantil e no Ensino Fundamental, em um curso de extensão que relaciona questões do ambiente, da escola e da sociedade. O objetivo do curso foi estimular um pensamento crítico, reflexivo e interdisciplinar sobre as questões relativas à temática ambiental, os encontros foram quinzenais, com tarefas e a produção de um projeto didático de Educação Ambiental como trabalho final. Os trabalhos analisados indicaram elementos importantes que os aproximam da perspectiva crítica de EA e da interdisciplinaridade.

Os resultados apresentados mostraram que dos 7.460 artigos analisados apenas 16 abordam a temática Educação Ambiental Crítica na formação de professores. Desse modo, fica evidente a necessidade de mais pesquisas relacionadas EAC na formação inicial e continuada de professores, visando à melhoria da formação docente.

\section{Considerações Finais}

Por meio desta pesquisa de Revisão Sistemática De Literatura, foi possível ter um panorama das publicações com a temática Educação Ambiental Crítica na formação de professores na Biblioteca Digital Brasileira de Teses e Dissertações do IBICT, no portal de periódicos da CAPES e dos periódicos de índice restrito em Ensino, com Qualis A1, A2 e B1, no período de 2000 a 2018. 
Por intermédio das informações contidas nas tabelas e nas análises realizadas nos trabalhos selecionados nesta pesquisa, emergem conhecimentos que buscam responder a QP1: A Educação Ambiental Crítica está presente na formação inicial e continuada de professores? Após a análise realizadas nas três bases de dados resultando em um total de 7.460 trabalhos, apenas 16 pesquisas abordam a temática de formação de professores, visando reconstruir, conceitos, refletir os aspectos políticos, econômicos, sociais e ambientais e superar a reducionismo da educação ambiental conservadora. Evidenciando assim uma carência de publicações a respeito da Educação Ambiental Crítica na formação inicial e continuada de professores.

Buscando responder a argumentação da QP2: De que forma a Educação Ambiental Crítica está sendo trabalhada na formação inicial e continuada de professores? Observa-se que a Educação Ambiental Crítica é implementada por meio da realização de cursos, pesquisa-ação, grupos de discussões, debates e oficinas, sendo trabalhada de maneira muito pontual. A formação de professores enquanto "sujeitos ecológicos" precisa encontrar espaço nos ambientes universitários e de formação continuada que promovam o desenvolvimento humanitário destes profissionais e orientem suas condutas dentro e fora da escola.

Para que professores atuem como agentes de mudança social na sociedade atual acometida pela crise ambiental, se faz necessário que os cursos de licenciatura propiciem em seus currículos aspectos educativos para formação de sujeitos éticos, críticos, reflexivo e emancipados. Não se pode compactuar com a ideia de que a formação de professores emancipados, éticos e críticos ambientalmente sejam constituídos apenas enquanto uma possibilidade ou reduzida a aspecto formativo "optativo".

Assim, se fazem necessários mais estudos para inserção da temática Educação Ambiental Crítica nos cursos de licenciatura e em cursos de formação continuada para preparar professores críticos comprometidos eticamente com a sociedade e com o ambiente, colaborando para a transformação social e para a melhoria da qualidade de vida. Visto que é um campo farto a ser explorado e de grande importância, devido a se tratar de uma temática obrigatória no âmbito educacional, é necessário profissionais qualificados para desenvolvê-la na Educação Básica e no Ensino Superior.

\section{Referências}

BRASIL. Lei n. 9.795 de 27 de abril de 1999. Dispõe sobre a educação ambiental, institui a Política Nacional de Educação Ambiental e dá outras providências. Diário Oficial da República Federativa do Brasil, Poder Executivo, Brasília, DF, 28 abr. 1999. Disponível em: http://www.planalto.gov.br/ccivil_03/LEIS/L9795.htm. Acesso em: 21 jan. 2019.

BRASIL. Resolução n. 2, de 15 de junho de 2012. Estabelece as Diretrizes Curriculares Nacionais para a Educação Ambiental. Diário Oficial da União, Brasília, n. 116, seção 1, p. 70, 18 jun. 2012. COSTA, L.; ECHEVERRÍA, A.; RIBEIRO, F. L. O Processo de Tomada de Consciência e a Formação de Conceitos da Educação Ambiental na Formação Inicial de Professores de Ciências/Química. Revista Brasileira de Pesquisa em Educação em Ciências, v. 17, n. 3, p. 803 -
834 ,
20
dez.
2017.
Disponível 
https://periodicos.ufmg.br/index.php/rbpec/article/view/4525/2979. Acesso em: 10 ago. 2018.

DIAS, Genebaldo Freire. Educação Ambiental: princípios e práticas. 9. ed. São Paulo: Gaia, 2010.

FLORENTINO, H. S. Os processos críticos-colaborativos em educação ambiental na formação continuada de professores contextualizada para o semiárido paraibano. 2018. 352 f. Tese (Doutorado em Educação) Universidade Federal da Paraíba, João Pessoa. 2018.

GUIMARÃES, M. Educação ambiental crítica. In: LAYRARGUES, P. P. Identidades da educação ambiental brasileira. Brasília: Ministério do Meio Ambiente, 2004.

GUIMARAES, S. S. M; INFORSATO, E. C. A percepção do professor de Biologia e a sua formação: a Educação Ambiental em questão. Ciências \& Educação (Bauru), Bauru , v. 18, n. 3, p. 737754, 2012 . Disponível em: http://www.scielo.br/scielo.php?script=sci_arttext\&pid=S1516$73132012000300016 \&$ lng=en\&nrm=iso.

Acesso

em:

13 ago. 2018. http://dx.doi.org/10.1590/S1516-73132012000300016.

KITCHENHAM, B. Guidelines for performing Systematic Literature Reviews in Software Engineering. EBSE Technical Report. EBSE-2007-01, Version 2.3, Keele University and University of Durham, 2007.

LOPES, T. M. Ações de formação continuada, baseadas na pedagogia dialógica, para a inserção da Educação Ambiental crítica em escolas públicas 2018. 216 f. Tese (Doutorado em Educação Escolar) - Universidade Estadual Paulista "Júlio de Mesquista Filho", Faculdade de Ciências e Letras (Campus Araraquara), São Paulo, 2018.

LOUREIRO, C. F. B. Trajetórias e fundamentos da Educação Ambiental. 4 ed. São Paulo, SP: Cortez Editora, 2012

MAIA, J. S. S. Educação ambiental crítica e formação de professores: construção coletiva de uma proposta na escola pública. 2011. 224 f. Tese (Doutorado em Educação pra Ciência) Universidade Estadual Paulista, Faculdade de Ciências, 2011. Disponível em: http://hdl.handle.net/11449/90964. Acesso em: 10 ago. 2018.

MARTINS, J. P. A. Educação ambiental crítica e formação de professoras fundada na investigação-ação e na parceria colaborativa. 2016. Tese (Doutorado em Educação) Universidade Metodista de Piracicaba, Piracicaba, 2016.

MARTINS, J. P. A.; SCHNETZLER, R. P. Formação de professores em educação ambiental crítica centrada na investigação-ação e na parceria colaborativa. Ciênc. educ. (Bauru), Bauru, v. 24, n. 3, p. 581-598, Set. 2018.2 Disponível em: http://www.scielo.br/scielo.php?script=sci_arttext\&pid=S1516-

$73132018000300581 \&$ Ing=en\&nrm=iso.

Acesso em: 15 fev. 2019. http://dx.doi.org/10.1590/1516-731320180030004.

MORALES, A. G. M. Processo de institucionalização da educação ambiental: tendências, correntes e concepções. Pesquisa em Educação Ambiental, Ponta Grossa, vol. 4, n. 1, p. 159175, 2009. 
OLIVEIRA, Laryssa Abílio. Educação Ambiental Crítica: círculos de cultura na formação continuada docente. 2018. 176 f. Tese (Doutorado) - Programa de Pós-Graduação em Educação, Universidade Federal da Paraíba, João Pessoa, 2018.

PENTEADO, H. D. Meio Ambiente e Formação de Professores. 6.ed. São Paulo: Cortez Editora, 2007.

PINTO, E. A. A formação de educadores ambientais críticos em um curso de pedagogia: limites e possibilidades. 2016. 327 f. Tese (Doutorado em Educação para Ciências) - Faculdade de Ciências da Universidade Estadual Paulista "Júlio de Mesquita Filho" - UNESP, Bauru, 2016.

RIBEIRO, T. G. O. Formação de professores em contexto para o desenvolvimento de práticas de Educação Ambiental Crítica na escola. 2016. 95f. Dissertação (Mestrado em Ensino de Ciências e Matemática) - Instituto Federal de Educação, Ciência e Tecnologia de São Paulo, IFSP, São Paulo, 2016.

ROCHA, A. G. Formação continuada para uma educação ambiental crítica: concepções de professores do ensino fundamental do município do Rio de Janeiro. 2016129 f. Dissertação (Mestrado em ensino em biociências e saúde) Instituto Oswaldo Cruz, FIOCRUZ, Rio de Janeiro, 2016.

ROSA, M. D.; NOGUEIRA, M. L. S. L.;SOUZA, J. P. T.; ROCHA, P. N.; RINK, J.; VIVEIRO, A. A. As perspectivas de ambiente e de Educação Ambiental nos projetos de professores da Educação Básica em um curso de formação continuada. Ambiente \& Educação - Revista de Educação Ambiental, [s.I.], v. 22, n. 2, p.88-108, 16 mar. 2018. Lepidus Tecnologia. http://dx.doi.org/10.14295/ambeduc.v22i2.7335.

SCHERK, L. Z. L. A formação continuada de professores em serviço em educação ambiental por meio da pesquisa-ação participante. 2014. 156 f. Dissertação (Mestrado) - Universidade Federal do ABC, Programa De Pós-Graduação em Ensino, História, Filosofia das Ciências e Matemática, 2014. Disponível em: http://biblioteca.ufabc.edu.br/index.php?codigo_sophia=95454. Acesso em: 10 ago. 2018.

SILVA, N F. Educação ambiental e formação de professores para a conservação da fauna do Parque Estadual das Fontes do Ipiranga (PEFI - SP). 2018. 120 f. Dissertação (Mestrado) - Curso de Programa de Pós-graduação em Conservação da Fauna, Departamento de Ciências Ambientais, Universidade Federal de São Carlos, São Carlos, 2018.

SOUZA, D. C. A Educação Ambiental Crítica e sua construção na escola pública: compreendendo contradições pelos caminhos da formação de professores. Tese (Doutorado em Educação para a Ciência) - Universidade Estadual Paulista. Faculdade de Ciências, Bauru, 2014.

TIBÚRCIO, G. S.; LOGAREZZI, A. J. M. A formação de educadoras/es ambientais a partir do Pibid: reflexões sobre limites e possibilidades. Pesquisa em Educação Ambiental, [s.I.], v. 12, n. 2, p.93-112, 24 fev. 2018. Departamento de Educação da Universidade Estadual Paulista - UNESP. http://dx.doi.org/10.18675/2177-580x.vol12.n2. p. 93-112. 